\title{
10. EFFECTS OF CORE RETRIEVAL AND DEGASSING ON THE CARBON ISOTOPE COMPOSITION OF METHANE IN GAS HYDRATE-AND FREE GAS-BEARING SEDIMENTS FROM THE BLAKE RIDGE ${ }^{1}$
}

\author{
Paul J. Wallace, ${ }^{2}$ Gerald R. Dickens, ${ }^{3}$ Charles K. Paull,, 45 and William Ussler III ${ }^{4}$
}

\begin{abstract}
Cores with sediment and gas from the gas hydrate reservoir on the Blake Ridge were recovered at near in situ pressure using the pressure core sampler (PCS) on Leg 164. Stepwise degassing of these cores and subsequent analyses of gas samples provide a unique data set concerning the in situ abundance and composition of gases in marine sediments. Carbon isotope analyses were conducted on $\mathrm{CH}_{4}$ from 90 of the gas samples to compare the isotopic composition of in situ $\mathrm{CH}_{4}$ with the isotopic composition of gas in sediments recovered by conventional coring procedures. Weighted averages of $\mathrm{CH}_{4} \delta^{4}{ }^{13} \mathrm{C}$ values from PCS cores at Sites 995 and 997 are relatively constant at $-65 \%$ o to $62 \%$ PDB between $300 \mathrm{~m}$ below seafloor (mbsf) and the bottom of the holes (700-750 mbsf). These values indicate a microbial origin for the methane. The weighted averages of $\mathrm{CH}_{4} \delta^{13} \mathrm{C}$ values for PCS gas samples are comparable to those for gas recovered from voids in standard advanced piston (APC) and extended core barrel (XCB) cores recovered from similar depths. This demonstrates that $\delta^{13} \mathrm{C}$ of $\mathrm{CH}_{4}$ in gas hydrate- and free gas-bearing sediments is not fractionated during degassing of normal cores, even though as much as $99.8 \%$ of the original $\mathrm{CH}_{4}$ in the sediments can be lost during core recovery. However, during degassing of a core inside of the PCS, anomalous methane $\delta^{13} \mathrm{C}$ values are frequently observed for the first degassing step, which involves release of $\mathrm{CH}_{4}$-poor air that is trapped inside the PCS during deployment. Experiments on degassing of $\mathrm{CH}_{4}$-saturated water in a simple, sediment-free system analogous to the PCS demonstrates that carbon isotope fractionation of $1.5 \%$ - $2 \%$ o between $\mathrm{CH}_{4}$ gas and dissolved $\mathrm{CH}_{4}$ can occur after large pressure drops if the system is not allowed to re-equilibrate. This fractionation effect is probably amplified during gas release from PCS core samples because gas must escape through fine-grained sediment. Kinetic fractionation of carbon isotopes likely accounts for some of the nonsystematic methane carbon isotopic variations that are observed during degassing of PCS cores.
\end{abstract}

\section{INTRODUCTION}

The amount, molecular distribution, and isotopic composition of hydrocarbon gases recovered in marine sediments have frequently been used to infer the origin of the gases and the fate of buried organic carbon (e.g., Claypool and Kaplan, 1974; Paull et al., Chap. 7, this volume). However, sediment cores recovered from deep water and at high pressure by normal coring techniques have lost hydrocarbon gases by the time cores arrive at the surface for sampling. The quantity of gas lost and any potential fractionation of the hydrocarbon distribution or isotopic composition have not been emphasized in the scientific literature because the technology to address these issuespressure coring with a manifold to collect gas volumes-had been unsuccessful prior to Leg 164 (Kvenvolden et al., 1983; Pettigrew, 1992; Paull, Matsumoto, Wallace, et al., 1996).

Leg 164 sites were drilled into a large reservoir of gas hydrateand free gas-bearing sediments on the Blake Ridge $\sim 200 \mathrm{~km}$ off the coast of South Carolina (Paull, Matsumoto, Wallace, et al., 1996; Dickens et al., 1997). The pressure core sampler (PCS), a tool designed to recover a $1385-\mathrm{cm}^{3}$ cylindrical sediment core at in situ pressure (Pettigrew, 1992), was used numerous times during Leg 164 with appropriate manifolds to successfully recover incremental gas volumes from pressurized cores of deep-sea sediment (Paull, Matsu-

${ }^{1}$ Paull, C.K., Matsumoto, R., Wallace, P.J., and Dillon, W.P. (Eds.), 2000. Proc. ODP, Sci. Results, 164: College Station, TX (Ocean Drilling Program).

${ }^{2}$ Ocean Drilling Program, Texas A\&M University, College Station, TX 77845, U.S.A.paul_wallace@odp.tamu.edu

${ }^{3}$ School of Earth Sciences, James Cook University, Townsville, QLD 4811 Australia

${ }^{4}$ Department of Geology, University of North Carolina, Chapel Hill, NC 275993315, U.S.A.

${ }^{5}$ Present address: Monterey Bay Aquarium Research Institute, 7700 Sandholdt Road, Moss Landing, CA 95039-0628, U.S.A. moto, Wallace, et al., 1996; Dickens et al., Chap. 43, this volume). Comparisons between the total amount of gas recovered by the PCS (Dickens et al., 1997, and Chaps. 43 and 11, this volume) and by conventional ODP coring techniques at the same depth (especially by XCB; see Paull, Matsumoto, Wallace, et al., 1996) can be striking: often in excess of $95 \%$ (and in some cases, at least 99.8\%) of the hydrocarbons were lost during the 20-30 min between conventional coring at depth and gas sampling on the surface.

An important issue is whether such extreme and rapid loss of gas from sediment during conventional core retrieval is associated with fractionation of the molecular distribution or isotopic composition of hydrocarbon gases. In this manuscript, we present carbon isotope measurements of $\mathrm{CH}_{4}$ released from sediment recovered using the PCS during Leg 164 . We show that the $\delta^{13} \mathrm{C}$ of individual gas increments can have a wide range in $\delta^{13} \mathrm{C}$ composition. However, the total $\delta^{13} \mathrm{C}$ of volumetrically weighted averages of gas samples from individual PCS cores is similar to the $\delta^{13} \mathrm{C}$ of gas sampled from gas voids in conventional sediment cores at comparable depths. We address the cause of carbon isotope variation in incremental gas volumes released from the PCS by comparing the PCS gas data with results of degassing experiments in simple, sediment-free analog systems. Data concerning total amounts of gas (predominantly $\mathrm{CH}_{4}$ ) and hydrocarbon composition from PCS cores are reported elsewhere (Paull, Matsumoto, Wallace, et al., 1996; Dickens et al., 1997, and Chaps. 43 and 11 , this volume).

\section{GASES FROM THE PRESSURE CORE SAMPLER Sample Collection}

Forty-two deployments (runs) of the PCS on Leg 164 successfully recovered a sediment core at high pressure (>3.45 MPa) at Sites 994, 995, 996, and 997 (Paull, Matsumoto, Wallace, et al., 1996; Dickens 
et al., Chaps. 43 and 11, this volume). Data collection for most of these cores generally proceeded as follows (Paull, Matsumoto, Wallace, et al., 1996; Dickens et al., Chap. 43, this volume). After core recovery, the PCS was placed in an ice bath, and a gas manifold system and sampling chamber were attached to an outlet port. Incremental volumes of gas were released from the PCS over time until the inside of the PCS was at atmospheric pressure. The PCS was removed from the ice bath and warmed to ambient temperature $\left(\sim 15^{\circ} \mathrm{C}\right)$. Additional volumes of gas were then collected. Aliquots of gas were taken from gas volume increments for compositional analyses.

Due to a variety of technical and operational reasons, there was a lack of experimental consistency with PCS operations during Leg 164 (see Paull, Matsumoto, Wallace, et al. [1996] and Dickens et al., [Chaps. 43 and 11, this volume], for details). Of particular importance for interpreting carbon isotope compositions of gas samples released from the PCS are (1) most cores were not given sufficient time to equilibrate after changes in pressure (and gas concentration), and (2) individual cores had different initial pressures, temperatures, gas concentrations, and sediment volumes.

The predominant hydrocarbon gas in all gas samples released from the PCS was $\mathrm{CH}_{4}\left(\mathrm{C}_{1} / \mathrm{C}_{2}>1100\right.$; Paull, Matsumoto, Wallace, et al., 1996).

\section{Carbon Isotope Analyses}

Ninety gas samples from stepwise degassing of 18 PCS cores recovered at Sites 994, 995, 996, and 997 were analyzed for $\mathrm{CH}_{4} \delta^{13} \mathrm{C}$ using a Finnigan MAT 252 mass spectrometer with a combustion interface at the University of North Carolina at Chapel Hill. The analytical procedure for the PCS samples was the same as that for $\mathrm{CH}_{4}$ collected from gas voids by the vacutainer method and is described by Paull et al. (Chap. 7, this volume). Measured carbon isotope ratios for PCS gas samples are expressed in delta notation relative to the Peedee belemnite (PDB) standard (Table 1). Analytical precision for the $\mathrm{CH}_{4} \delta^{13} \mathrm{C}$ values based on replicate gas analyses was typically \pm 0.2 or less $(1 \sigma)$.

\section{Observations}

Figure 1 shows downhole profiles of $\mathrm{CH}_{4} \delta^{13} \mathrm{C}$ for gas samples that were taken from gas expansion voids in APC and XCB cores from Sites 994, 995, and 997 (Paull et al., Chap. 7, this volume). Methane $\delta^{13} \mathrm{C}$ for gas voids increases from minimum values of $-85 \%$ to $-80 \%$ at $\sim 40$ mbsf to relatively constant values of $-65 \%$ o to $-62 \%$ o between $300 \mathrm{mbsf}$ and the bottom of the holes (700-750 mbsf) at Sites 995 and 997. At depths greater than $200 \mathrm{mbsf}, \mathrm{CH}_{4}$ recovered from gas voids at Site 994 shows considerably more scatter in carbon isotopic composition than $\mathrm{CH}_{4}$ recovered from gas voids at Sites 995 and 997. The cause of this scatter is unknown. It could be the result of greater natural variability of $\mathrm{CH}_{4} \delta^{13} \mathrm{C}$ in Site 994 sediments compared with 995 and 997 . Alternatively, it may be an artifact of sample handling and storage of the Site 994 gases.

Also shown in Figure 1 are $\mathrm{CH}_{4} \delta^{13} \mathrm{C}$ values for PCS gas samples from Sites 994, 995, and 997. Although only a small number of PCS gas samples from Site 994 were analyzed for $\mathrm{CH}_{4} \delta^{13} \mathrm{C}$, values fall within the range defined by the data for gas voids. At Sites 995 and 997, multiple gas samples were taken from numerous PCS cores during depressurization of the PCS. For PCS gas samples from Site 995, $\mathrm{CH}_{4} \delta^{13} \mathrm{C}$ values from an individual core vary by as much as $9 \%$ (Fig. 1). The range in $\mathrm{CH}_{4} \delta^{13} \mathrm{C}$ values for successive gas samples from individual PCS cores at Site 995 typically vary from a value that is significantly lighter than the trend defined by gas void data to maximum values that lie on the trend. In contrast to Site 995, the range of $\mathrm{CH}_{4}$ $\delta^{13} \mathrm{C}$ values for PCS gas samples from Site 997 straddles the trend defined by the gas void data (Fig. 1).

Gas samples collected from the PCS have been numbered sequentially according to when the gas was released from the PCS during pressure loss (Dickens et al., Chap. 43, this volume). Shown in Figures 2 and 3 are time series plots of $\mathrm{CH}_{4} \delta^{13} \mathrm{C}$ values for gas samples taken from individual PCS cores at Sites 995 and 997, respectively. All cores from Site 995 are characterized by an increase in $\mathrm{CH}_{4} \delta^{13} \mathrm{C}$ over time and pressure loss. The large (up to 9\%o) spread in $\mathrm{CH}_{4} \delta^{13} \mathrm{C}$ for gas from Cores 164-995A-27P, 36P, and 45P results from an initial degassing step in which $\delta^{13} \mathrm{C}$ is much lighter than subsequent steps. Patterns for PCS cores from Site 997 are less systematic, although Cores 164-997A-25P and 21P also show gradual increases in the $\mathrm{CH}_{4} \delta^{13} \mathrm{C}$ throughout the degassing sequence (Fig. 3). In contrast to all other PCS cores, the initial gas volume released from Core 164997A-49P has a significantly heavier $\delta^{13} \mathrm{C}$ (by $~ 2 \%$ ) than samples released at lower pressure. Data for $\mathrm{CH}_{4} \delta^{13} \mathrm{C}$ in gas samples from two PCS cores taken at Site 996, a shallow hole located above the Blake Ridge Diapir (Paull, Matsumoto, Wallace, et al., 1996), show patterns generally similar to those observed in the Site 995 and 997 PCS data, with variations as much as $3 \%$ (Fig. 4).

During controlled degassing of a PCS core, the first (and sometimes second) degassing step usually releases a small volume of $\mathrm{CH}_{4}$ poor gas at high pressure (Paull, Matsumoto, Wallace, et al., 1996; Dickens et al., Chaps. 43 and 11, this volume). The composition of this gas is dominantly air that is trapped inside the PCS chamber during deployment, or helium that is used to purge the manifold prior to gas release. Subsequent degassing steps at lower pressure contain mostly $\mathrm{CH}_{4}$ (Table 1). In Figures 5, 6, and 7, the $\mathrm{CH}_{4} \delta^{13} \mathrm{C}$ value of each gas sample is plotted against the volume of $\mathrm{CH}_{4}$ released in the degassing step from which the gas sample was taken for isotopic analysis. Also shown is the average value for $\mathrm{CH}_{4} \delta^{13} \mathrm{C}$ weighted according to the volume of $\mathrm{CH}_{4}$ released in each degassing step. The results show that anomalous $\mathrm{CH}_{4} \delta^{13} \mathrm{C}$ values in PCS gas samples commonly correspond to degassing steps involving small volumes of $\mathrm{CH}_{4}$ The results also show that the volumetrically weighted average of $\mathrm{CH}_{4} \delta^{13} \mathrm{C}$ values for all gas samples collected from a PCS core are within $1 \%$ of $\mathrm{CH}_{4} \delta^{13} \mathrm{C}$ values collected from gas voids of APC and $\mathrm{XCB}$ cores at similar depth (Fig. 1; Table 1).

In contrast, $\mathrm{CO}_{2} \delta^{13} \mathrm{C}$ values of PCS gas samples are highly variable and mostly much lighter than $\mathrm{CO}_{2} \delta^{13} \mathrm{C}$ of gas voids from APC and XCB cores recovered at comparable depths (Paull et al., Chap. 7, this volume). Given that $\mathrm{CO}_{2}$ accounts for only a small fraction of the total gas ( $\leq 2 \%$ by volume), it is likely that $\mathrm{CO}_{2} \delta^{13} \mathrm{C}$ values of PCS gas samples are biased to some extent by methane oxidation during sample handling. However, no correlation is observed between $\mathrm{CH}_{4}$ $\delta^{13} \mathrm{C}$ and $\mathrm{CO}_{2} \delta^{13} \mathrm{C}$ in PCS gas samples, suggesting that oxidation effects do not change $\mathrm{CH}_{4} \delta^{13} \mathrm{C}$ appreciably.

\section{GAS FRACTIONATION EXPERIMENTS IN SIMPLE ANALOG SYSTEMS}

\section{Experimental}

The range in $\mathrm{CH}_{4} \delta^{13} \mathrm{C}$ values for PCS gas samples from individual cores (as much as $9 \%$ ) is significantly greater than the analytical uncertainty $(2 \sigma= \pm 0.4 \%$ ) . A possible explanation for these large variations is that kinetic fractionation of $\mathrm{CH}_{4} \delta^{13} \mathrm{C}$ is occurring during degassing of the PCS (as well as in uncontrolled degassing of APC and $\mathrm{XCB}$ cores). The observation that $\mathrm{CH}_{4} \delta^{13} \mathrm{C}$ values vary depending on the volume of $\mathrm{CH}_{4}$ released indeed suggests that carbon isotope fractionations result from kinetic (nonequilibrium) effects during degassing.

To isolate causes of the observed fractionation of $\mathrm{CH}_{4}$ carbon isotopes, we performed shore-based degassing experiments in simple systems analogous to the shipboard degassing experiments with the PCS. The first set of experiments involved releasing methane from a pressure vessel into a bubbling chamber identical to that used during Leg 164 PCS experiments (Fig. 8; see also Paull, Matsumoto, Wallace, et al., 1996). The second set of experiments involved degassing of $\mathrm{CH}_{4}$ gas-saturated water from the pressure vessel (Fig. 9). 
Table 1. Compositional and isotopic data for PCS gas samples.

\begin{tabular}{|c|c|c|c|c|c|}
\hline Sample & $\begin{array}{l}\text { Depth } \\
\text { (mbsf) }\end{array}$ & $\begin{array}{c}\text { Gas } \\
\text { volume } \\
(\mathrm{mL})\end{array}$ & $\begin{array}{c}\mathrm{CH}_{4} \\
(\mathrm{ppm})\end{array}$ & $\begin{array}{c}\mathrm{CH}_{4} \\
\text { volume } \\
(\mathrm{mL})\end{array}$ & $\begin{array}{l}\delta^{13} \mathrm{C}\left(\mathrm{CH}_{4}\right) \\
(\% \circ \mathrm{PDB})\end{array}$ \\
\hline $\begin{array}{l}164-994 \mathrm{C}-27 \mathrm{P} \\
\text { G2 } \\
\text { G3 }\end{array}$ & 223.50 & 二 & $\begin{array}{l}231,900 \\
393,800\end{array}$ & - & $\begin{array}{l}-67.0 \\
-67.9\end{array}$ \\
\hline $\begin{array}{l}\text { 164-994C-36P } \\
\text {-2 }\end{array}$ & 300.40 & - & 225,000 & - & -61.1 \\
\hline 164-994C-60P & 541.10 & - & 228,400 & - & -64.3 \\
\hline 164-994C-70P & 569.90 & - & 789,800 & - & -63.0 \\
\hline $\begin{array}{l}\text { 164-995A-27P } \\
\text { G1 } \\
\text { G2 } \\
\text { G3 } \\
\text { G5 } \\
\text { G6 }\end{array}$ & 222.90 & $\begin{array}{l}105 \\
860 \\
840 \\
920 \\
560\end{array}$ & $\begin{array}{r}19,400 \\
837,000 \\
953,700 \\
914,100 \\
912,100\end{array}$ & $\begin{array}{c}2.0 \\
719.8 \\
801.1 \\
841.0 \\
510.8 \\
\text { Weighted avg.: } \\
\text { Weighted std. dev.: }\end{array}$ & $\begin{array}{r}-71.3 \\
-67.7 \\
-68.2 \\
-69.3 \\
-68.4 \\
-68.4 \\
0.6\end{array}$ \\
\hline $\begin{array}{l}\text { 164-995A-36P } \\
\text { G1 } \\
\text { G2 } \\
\text { G3 } \\
\text { G4 }\end{array}$ & 300.30 & $\begin{array}{r}80 \\
290 \\
590 \\
350\end{array}$ & $\begin{array}{r}24,700 \\
579,100 \\
970,200 \\
966,500\end{array}$ & $\begin{array}{c}2.0 \\
167.9 \\
572.4 \\
338.3 \\
\text { Weighted avg.: } \\
\text { Weighted std. dev.: }\end{array}$ & $\begin{array}{r}-71.4 \\
-65.9 \\
-66.0 \\
-65.0 \\
-65.7 \\
0.5\end{array}$ \\
\hline $\begin{array}{l}164-995 \mathrm{~A}-45 \mathrm{P} \\
\text { G1 } \\
\text { G2 } \\
\text { G3 } \\
\text { G8 }\end{array}$ & 377.50 & $\begin{array}{l}100 \\
175 \\
700 \\
170\end{array}$ & $\begin{array}{r}400 \\
50,900 \\
-\end{array}$ & $\begin{array}{l}0.0 \\
8.9 \\
- \\
-\end{array}$ & $\begin{array}{l}-73.5 \\
-64.9 \\
-63.9 \\
-63.9\end{array}$ \\
\hline $\begin{array}{l}\text { 164-995A-48P } \\
\text { G1 } \\
\text { G2 } \\
\text { G3 } \\
\text { G4 }\end{array}$ & 396.80 & $\begin{array}{r}85 \\
40 \\
425 \\
140\end{array}$ & $\begin{array}{r}40,900 \\
146,500 \\
610,100 \\
664,900\end{array}$ & $\begin{array}{c}3.5 \\
5.9 \\
259.3 \\
93.1 \\
\text { Weighted avg.: } \\
\text { Weighted std. dev.: }\end{array}$ & $\begin{array}{r}-65.0 \\
-65.0 \\
-63.9 \\
-63.4 \\
-63.8 \\
0.3\end{array}$ \\
\hline $\begin{array}{l}\text { 164-995A-60P } \\
\text { G1 } \\
\text { G2 } \\
\text { G3 } \\
\text { G4 }\end{array}$ & 493.10 & $\begin{array}{l}70 \\
640 \\
325 \\
275\end{array}$ & $\begin{array}{c}7,200 \\
195,700 \\
=\end{array}$ & $\begin{array}{r}0.5 \\
125.2 \\
- \\
-\end{array}$ & $\begin{array}{l}-67.3 \\
-65.2 \\
-64.2 \\
-63.4\end{array}$ \\
\hline $\begin{array}{l}\text { 164-995B-7P } \\
\text { G6B } \\
\text { G7B }\end{array}$ & 308.51 & $\overline{650}$ & 二 & - & $\begin{array}{l}-65.3 \\
-65.1\end{array}$ \\
\hline $\begin{array}{l}\text { 164-996A-7P } \\
\text { G3 } \\
\text { G4 } \\
\text { G6 } \\
\text { G8 } \\
\text { G16 } \\
\text { G17 } \\
\text { G19 } \\
\text { G22 } \\
\text { G24 }\end{array}$ & 47.50 & $\begin{array}{r}35 \\
45 \\
90 \\
300 \\
490 \\
600 \\
520 \\
280 \\
335\end{array}$ & $\begin{array}{r}31,300 \\
542,500 \\
864,000 \\
986,000 \\
948,700 \\
964,800 \\
972,700 \\
983,500 \\
932,400\end{array}$ & $\begin{array}{c}1.1 \\
24.4 \\
77.8 \\
295.8 \\
464.9 \\
578.9 \\
505.8 \\
275.4 \\
312.4 \\
\text { Weighted avg.: } \\
\text { Weighted std. dev.: }\end{array}$ & $\begin{array}{l}-69.4 \\
-69.3 \\
-68.7 \\
-68.8 \\
-68.0 \\
-68.4 \\
-68.4 \\
-70.6 \\
-68.5 \\
-68.6 \\
0.7\end{array}$ \\
\hline $\begin{array}{l}\text { 164-996D-7P } \\
\text { G5 } \\
\text { G7 } \\
\text { G9 } \\
\text { G10 } \\
\text { G11 } \\
\text { G12 } \\
\text { G13 } \\
\text { G14 } \\
\text { G15 }\end{array}$ & 51.20 & $\begin{array}{r}620 \\
215 \\
1060 \\
525 \\
525 \\
650 \\
440 \\
990 \\
550\end{array}$ & $\begin{array}{l}996,800 \\
956,000 \\
984,400 \\
988,900 \\
990,500 \\
953,500 \\
968,000 \\
941,400 \\
-\end{array}$ & $\begin{array}{c}618.0 \\
205.5 \\
1043.5 \\
519.2 \\
520.0 \\
619.8 \\
425.9 \\
932.0 \\
\text { Weighted avg.: } \\
\text { Weighted std. dev.: }\end{array}$ & $\begin{array}{l}-69.1 \\
-68.0 \\
-68.3 \\
-69.3 \\
-66.0 \\
-66.8 \\
-66.3 \\
-67.6 \\
-67.6 \\
-67.8 \\
1.1\end{array}$ \\
\hline
\end{tabular}

\section{Fractionation During Degassing of Pressurized Methane}

The first set of experiments was designed to test whether significant fractionation of carbon isotopes could occur during high pressure release of $\mathrm{CH}_{4}$. Four series of degassing experiments were performed, one each at 500, 1000, 1500, and 2000 psi. For each experiment, the pressure vessel did not contain water. Plastic spacers were used inside the pressure vessel to reduce the total gas volume. This made the void space inside the vessel comparable to that in the sec-

\begin{tabular}{|c|c|c|c|c|c|}
\hline Sample & $\begin{array}{l}\text { Depth } \\
\text { (mbsf) }\end{array}$ & $\begin{array}{c}\text { Gas } \\
\text { volume } \\
(\mathrm{mL})\end{array}$ & $\begin{array}{c}\mathrm{CH}_{4} \\
(\mathrm{ppm})\end{array}$ & $\begin{array}{c}\mathrm{CH}_{4} \\
\text { volume } \\
(\mathrm{mL})\end{array}$ & $\begin{array}{r}\delta^{13} \mathrm{C}\left(\mathrm{CH}_{4}\right) \\
(\% 0 \mathrm{PDB})\end{array}$ \\
\hline $\begin{array}{l}\text { 164-997A-25P } \\
\text { G1 } \\
\text { G2 } \\
\text { G3 } \\
\text { G4 }\end{array}$ & 202.40 & $\begin{array}{r}45 \\
15 \\
660 \\
340\end{array}$ & $\begin{array}{r}3,187 \\
24,448 \\
954,449 \\
948,136\end{array}$ & $\begin{array}{c}0.1 \\
0.4 \\
629.9 \\
322.4 \\
\text { Weighted avg.: } \\
\text { Weighted std. dev.: }\end{array}$ & $\begin{array}{r}-69.1 \\
-68.4 \\
-67.9 \\
-67.3 \\
-67.7 \\
0.3\end{array}$ \\
\hline $\begin{array}{l}\text { 164-997A-49P } \\
\text { G1 } \\
\text { G2 } \\
\text { G3 } \\
\text { G4 } \\
\text { G5 } \\
\text { G6 } \\
\text { G7 } \\
\text { G8 } \\
\text { G9 } \\
\text { G10 }\end{array}$ & 394.90 & $\begin{array}{r}110 \\
55 \\
540 \\
540 \\
290 \\
305 \\
685 \\
1190 \\
535 \\
165\end{array}$ & $\begin{array}{r}2,726 \\
672,426 \\
923,753 \\
950,344 \\
929,239 \\
897,917 \\
905,328 \\
931,182 \\
873,598 \\
512,814\end{array}$ & $\begin{array}{c}0.3 \\
37.0 \\
498.8 \\
513.2 \\
269.5 \\
273.9 \\
620.1 \\
1108.1 \\
467.4 \\
84.6 \\
\text { Weighted avg.: } \\
\text { Weighted std. dev.: }\end{array}$ & $\begin{array}{r}-62.4 \\
-64.1 \\
-64.0 \\
-64.8 \\
-64.4 \\
-64.2 \\
-64.6 \\
-64.2 \\
-64.7 \\
-64.7 \\
-64.4 \\
0.3\end{array}$ \\
\hline $\begin{array}{l}164-997 \mathrm{~A}-55 \mathrm{P} \\
\text { G1 } \\
\text { G2 } \\
\text { G3 } \\
\text { G4 } \\
\text { G6 } \\
\text { G7 } \\
\text { G9 }\end{array}$ & 433.30 & $\begin{array}{l}440 \\
690 \\
670 \\
560 \\
565 \\
630 \\
280\end{array}$ & $\begin{array}{l}745,193 \\
903,547 \\
920,593 \\
927,895 \\
949,175 \\
949,178 \\
928,040\end{array}$ & $\begin{array}{c}327.9 \\
623.4 \\
616.8 \\
519.6 \\
536.3 \\
598.0 \\
259.9 \\
\text { Weighted avg.: } \\
\text { Weighted std. dev.: }\end{array}$ & $\begin{array}{r}-64.7 \\
-64.1 \\
-64.0 \\
-64.3 \\
-64.9 \\
-63.9 \\
-63.6 \\
-64.2 \\
0.4\end{array}$ \\
\hline $\begin{array}{l}\text { 164-997B-10P } \\
\text { G3 } \\
\text { G4 } \\
\text { G5 } \\
\text { G6 } \\
\text { G7 } \\
\text { G8 } \\
\text { G9 } \\
\text { G10 } \\
\text { G11 }\end{array}$ & 462.20 & $\begin{array}{l}780 \\
465 \\
105 \\
105 \\
465 \\
465 \\
445 \\
575 \\
140\end{array}$ & $\begin{array}{r}\overline{-} \\
923,647 \\
924,586 \\
929,592 \\
917,494 \\
900,842 \\
894,195 \\
871,929\end{array}$ & $\begin{array}{c}429.5 \\
\overline{\bar{y} .1} \\
432.3 \\
426.6 \\
400.9 \\
514.2 \\
122.1 \\
\text { Weighted avg.: } \\
\text { Weighted std. dev.: }\end{array}$ & $\begin{array}{r}-63.3 \\
-63.5 \\
-63.2 \\
-64.6 \\
-63.0 \\
-64.4 \\
-63.5 \\
-63.2 \\
-65.0 \\
-63.6 \\
0.6\end{array}$ \\
\hline $\begin{array}{l}164-997 \mathrm{~B}-15 \mathrm{P} \\
\text { G2 } \\
\text { G3 } \\
\text { G4 } \\
\text { G5 } \\
\text { G6 } \\
\text { G7 }\end{array}$ & 501.80 & $\begin{array}{r}500 \\
1160 \\
510 \\
430 \\
525 \\
20\end{array}$ & $\begin{array}{l}874,613 \\
860,744 \\
878,845 \\
850,141 \\
874,108 \\
976,319\end{array}$ & $\begin{array}{c}437.3 \\
998.5 \\
448.2 \\
365.6 \\
458.9 \\
19.5 \\
\text { Weighted avg.: } \\
\text { Weighted std. dev.: }\end{array}$ & $\begin{array}{r}-64.4 \\
-63.1 \\
-63.4 \\
-65.5 \\
-63.2 \\
-65.0 \\
-63.7 \\
0.9\end{array}$ \\
\hline $\begin{array}{l}164-997 \mathrm{~B}-21 \mathrm{P} \\
\text { G1 } \\
\text { G2 } \\
\text { G3 } \\
\text { G4 } \\
\text { G5 } \\
\text { G6 } \\
\text { G7 } \\
\text { G8 }\end{array}$ & 549.90 & $\begin{array}{r}85 \\
85 \\
390 \\
960 \\
625 \\
530 \\
440 \\
340\end{array}$ & $\begin{array}{r}17,517 \\
8,006 \\
915,858 \\
957,771 \\
924,014 \\
890,910 \\
893,655 \\
-\end{array}$ & $\begin{array}{c}1.5 \\
0.7 \\
357.2 \\
919.5 \\
577.5 \\
472.2 \\
393.2 \\
- \\
\text { Weighted avg.: } \\
\text { Weighted std. dev.: }\end{array}$ & $\begin{array}{r}-64.3 \\
-64.2 \\
-63.1 \\
-63.0 \\
-62.7 \\
-63.3 \\
-62.8 \\
-62.0 \\
-63.0 \\
0.2\end{array}$ \\
\hline
\end{tabular}

Notes: $-=$ not measured. Successive aliquots of gas removed from each PCS core were numbered sequentially as $\mathrm{G} 1, \mathrm{G} 2, \mathrm{G} 3$, etc.

ond set of experiments in which water was present in the vessel. The pressure vessel was pressurized using $\mathrm{CH}_{4}$ with $2 \% \mathrm{CO}_{2}$. After the final pressure was reached, the intake valve was closed, and the pressure vessel was allowed to equilibrate for $\sim 5 \mathrm{~min}$. Both the pressure and temperature in the vessel stabilized in less than $30 \mathrm{~s}$ after closing the intake valve. After recording the pressure at the pressure transducer (located in the sampling tube), a valve was closed to isolate gas at pressure in a short section of tubing to which the pressure transducer was attached (Fig. 8). The outlet valve was then opened, allowing 
A

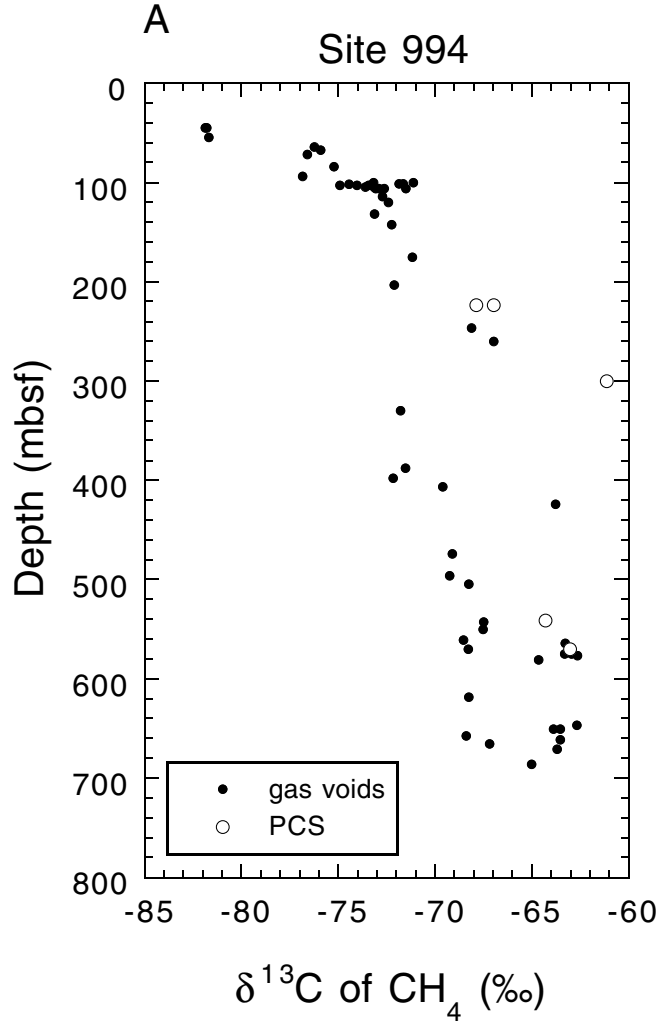

B

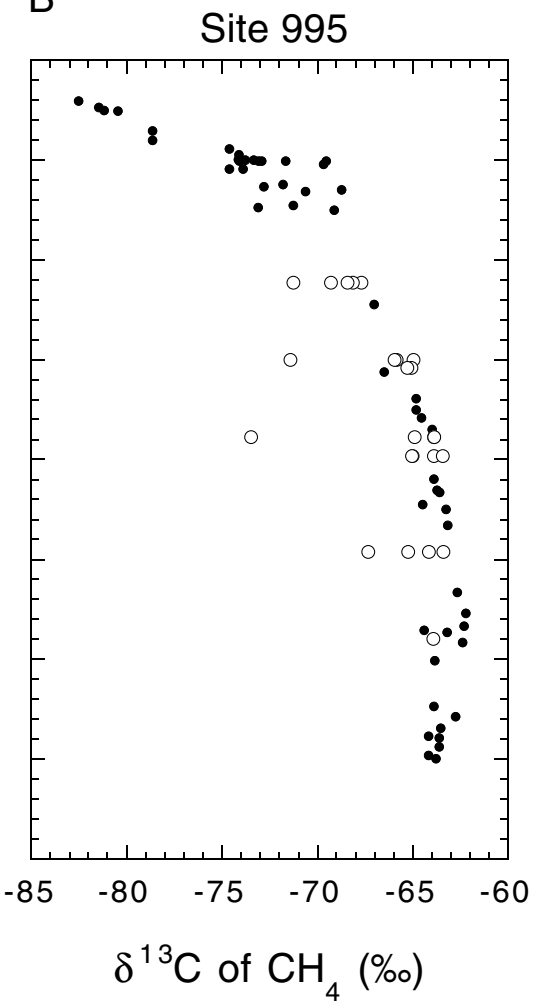

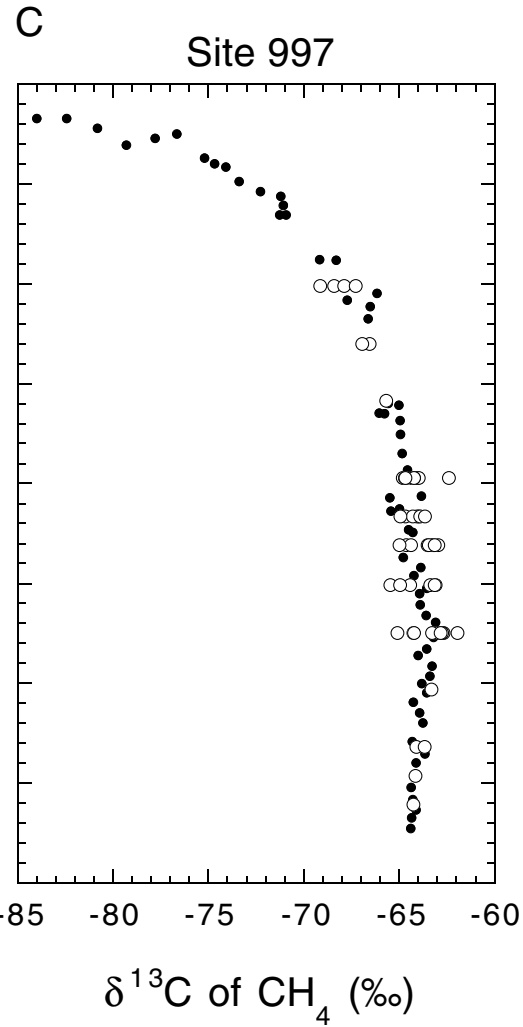

Figure 1. Methane $\delta^{13} \mathrm{C}$ values plotted against depth of recovery for samples derived from gas voids in APC and XCB cores (solid circles) and from degassing of pressurized cores in the PCS (open circles) during Leg 164. Isotopic data for PCS gas samples are in Table 1. Data for gas voids are in Paull et al. (Chap. 7, this volume). A. Site 994. B. Site 995. C. Site 997.

the gas to escape into a bubbling chamber consisting of an overturned graduated cylinder in $\mathrm{NaCl}$-saturated water. The volume of gas released was then measured to the nearest $10 \mathrm{~mL}$, and a sample of gas was taken for isotopic analysis using a plastic syringe. The outlet valve was then closed, and the valve connecting the pressure vessel to the sampling tube and pressure transducer was again opened. After waiting $2 \mathrm{~min}$, this valve was again closed and the pressure at the pressure transducer was recorded. The outlet valve then was opened releasing gas into the bubbling chamber. This procedure was repeated a third time. For the experiments conducted at 1500 and $2000 \mathrm{psi}$, in any single degassing step, all of the gas in the sampling tube could not be released at once, as the volume would have exceeded the $1 \mathrm{~L}$ capacity of the overturned graduated cylinder in the bubbling chamber.

\section{Fractionation During Degassing of Pressurized Methane and Gas-Saturated Water}

The second set of experiments was designed to assess carbon isotope fractionation between $\mathrm{CH}_{4}$ gas and $\mathrm{CH}_{4}$ gas-saturated water during rapid degassing. All experiments were performed at $\sim 1000$ psi. For each experiment, the pressure vessel was pressurized using the same tank of $\mathrm{CH}_{4}$ (with $2 \% \mathrm{CO}_{2}$ ) used in the first series of experiments. The inlet tube extended to near the bottom of the pressure vessel, which was about $90 \%$ filled with water, so that the methane bubbled through the water to facilitate equilibrium. After a pressure of $\sim 1050$ psi was reached, the vessel was allowed to equilibrate for 10$12 \mathrm{hr}$. The apparatus was designed so that a small aliquot of the headspace gas could be isolated in the sampling tube and, almost simultaneously, $\mathrm{CH}_{4}$-saturated water could be released back out of the inlet port directly into syringes (Fig. 9). When this occurred, the water effervesced vigorously, and the final amounts of water and evolved gas in the syringes could be measured. After the water samples were tak- en, the outlet valve was opened and the sample of headspace gas was introduced into the bubbling chamber, from which the gas was sampled with a syringe (Fig. 9). A second sample of headspace gas was isolated in the sampling tube following the large decrease in pressure in the vessel caused by release of $\mathrm{CH}_{4}$-saturated water. This gas was then released to the bubble chamber for sampling.

Three separate experiments were performed at 1000 psi. Between each, the pressure vessel was entirely vented to atmospheric pressure, and nitrogen bubbled through the water before the vessel was resealed and pressurized again. In the second and third experiments, a sample of $\mathrm{CH}_{4}$-saturated water at lower pressure was also taken after higher pressure samples were taken according to the procedures described above.

\section{Experimental Results}

Measurements of $\mathrm{CH}_{4} \delta^{13} \mathrm{C}$ for gas samples derived from the degassing experiments were made using the same instrument and procedures as already described for analysis of the PCS gas samples. Results of the experiments are presented in Tables 2 and 3. Methane $\delta^{13} \mathrm{C}$ values of gases from the first set of experiments on pressurized methane are shown in Figure 10. The results show that during a single degassing experiment, $\delta^{13} \mathrm{C}$ values may vary by as much as $1 \%$, but no systematic patterns are observed. Because no water was present in the pressure vessel during the experiments, the only processes that could be leading to these fractionations are (1) rapid flow of gas through tubing to the bubble chamber, (2) bubbling of methane through NaCl-saturated water in the bubbling chamber, and (3) sample handling as gas is removed from the bubbling chamber using a syringe and then transferred to an inverted gas bottle submerged in water.

Results of the $\mathrm{CH}_{4}$-saturated water degassing experiments are shown in Figure 11. Three separate experiments were run at $\sim 1000$ 

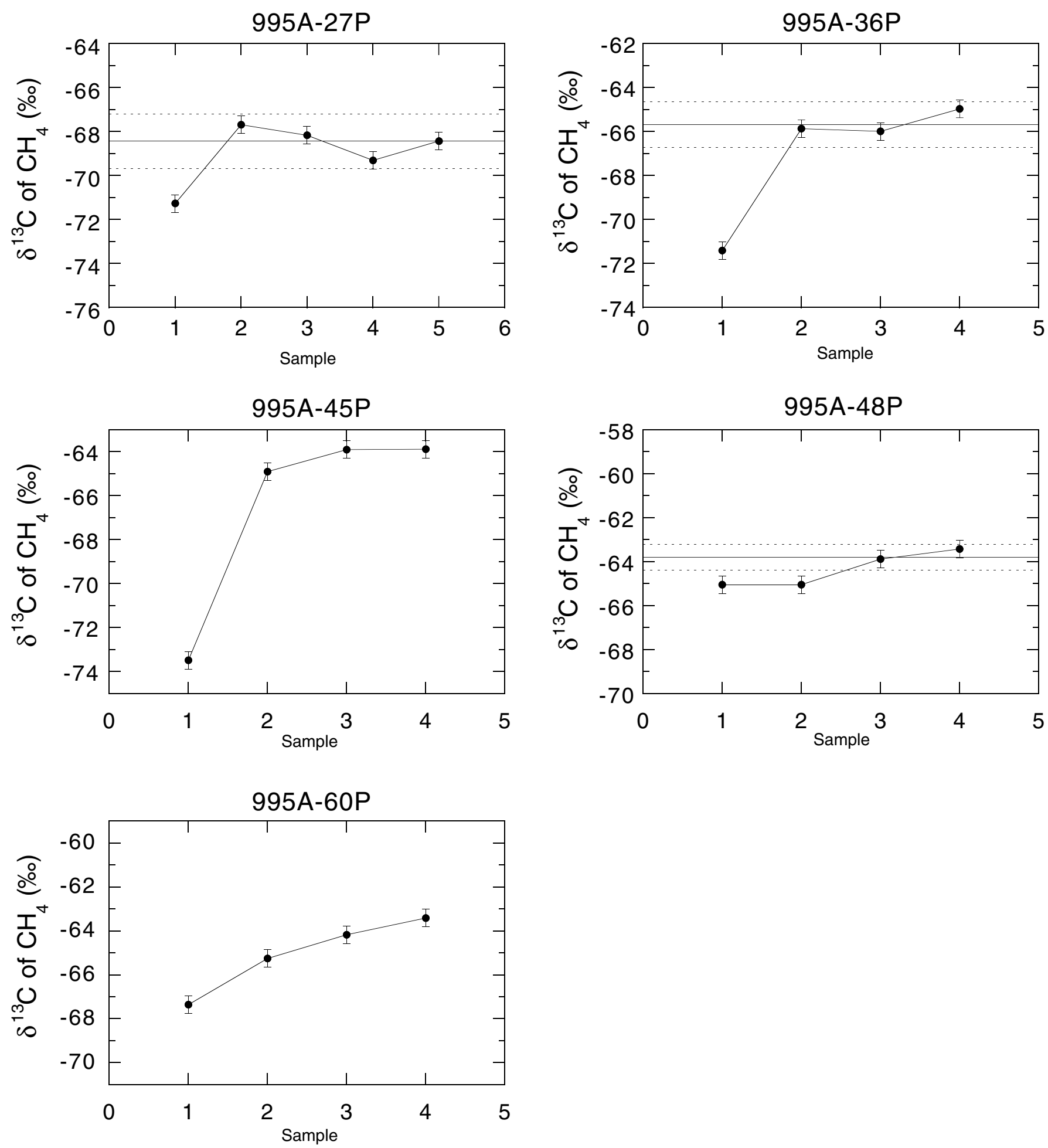

Figure 2. Times series plots of methane $\delta^{13} \mathrm{C}$ values from PCS cores at Site 995 . Each panel shows data from a single PCS core. Gases were evolved sequentially from the PCS, with the first gas sample released and collected labelled as Sample 1 (see text and Paull, Matsumoto, Wallace, et al., 1996, for details). The scale of the vertical axes is the same in all panels. Error bars show analytical uncertainties of 2 standard deviations $\left( \pm 0.4 \%\right.$ ). For each core, the average $\delta^{13} \mathrm{C}$ value calculated by weighting the individual measurements by the volume of $\mathrm{CH}_{4}$ released is shown by a horizontal line ( $\pm 2 \sigma$ uncertainty shown as dashed line). Average $\delta^{13} \mathrm{C}$ values could not be calculated for Cores 164-995A-45P and 60P because the volume was not measured for all gas aliquots. 

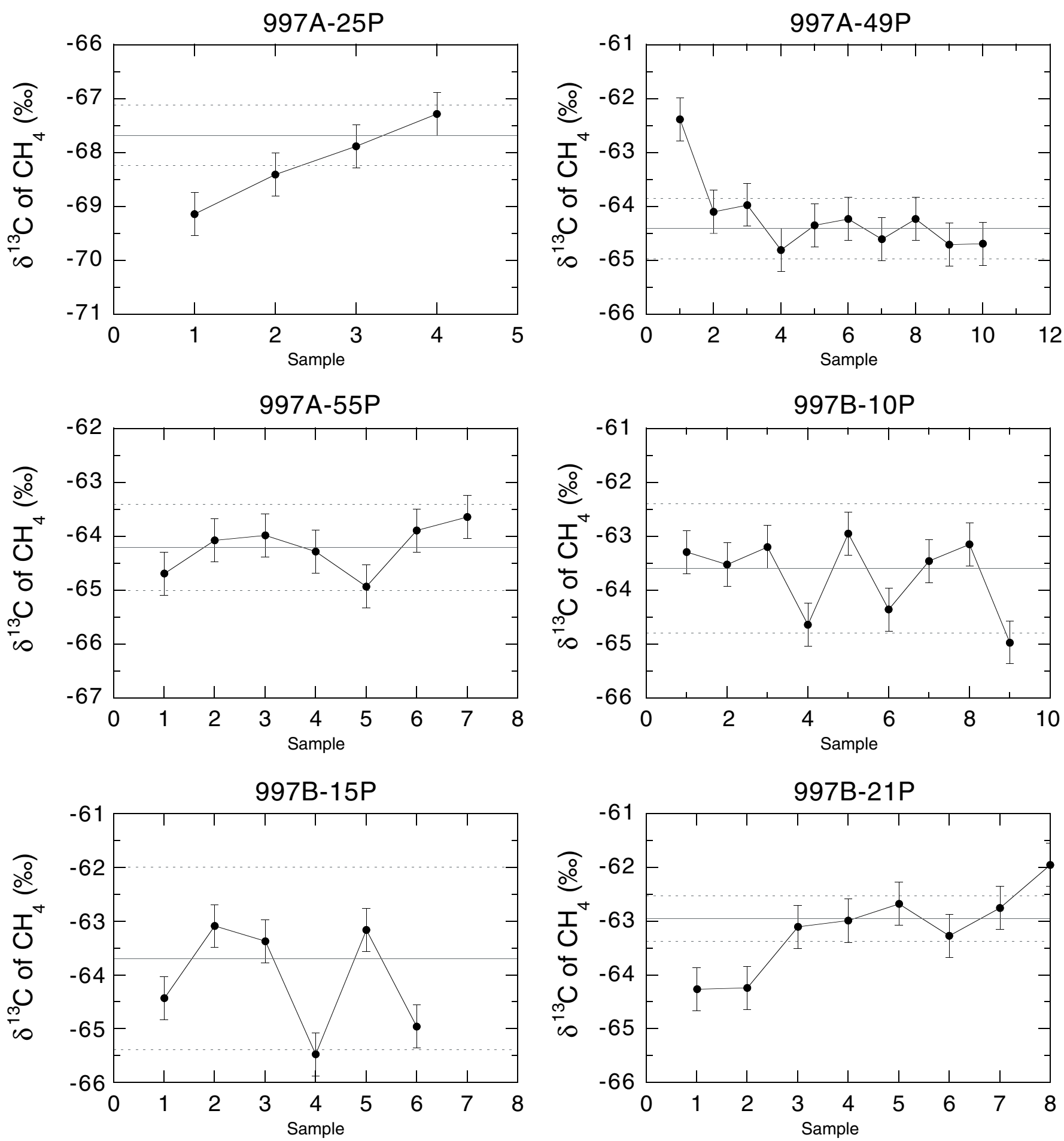

Figure 3. Times series plots of methane $\delta^{13} \mathrm{C}$ values from PCS cores at Site 997. Details as in Figure 2.

psi. Variability of methane $\delta^{13} \mathrm{C}$ values in each of the experiments exceeds the $2 \sigma$ analytical uncertainty of $\pm 0.4 \%$ o. Although there is considerable scatter in the data, there is no evidence of an equilibrium carbon isotope fractionation between $\mathrm{CH}_{4}$ gas and $\mathrm{CH}_{4}$ dissolved in water, because the high-pressure headspace gas and dissolved $\mathrm{CH}_{4}$ (water + gas in Fig. 11) are indistinguishable within analytical uncertainty in the second and third experiment (Figs. 11B, 11C). In the first and third experiments (Figs. 11A, 11C), isotope fractionation as great as $1.5 \%$ is observed for the headspace gas samples collected after passing through the bubbling chamber. In contrast, aliquots of $\mathrm{CH}_{4}$ exsolved from $\mathrm{CH}_{4}$-saturated water (water + gas in Fig. 11) show a more restricted range of $\delta^{13} \mathrm{C}$ variation.

Release of $\mathrm{CH}_{4}$-saturated water caused a large pressure drop inside the pressure vessel. Several minutes after this pressure drop (to $\sim 200$ psi) occurred, a new sample of headspace gas, which undoubtedly contained some $\mathrm{CH}_{4}$ just released from solution, was isolated in the sampling tube and then released to the bubbling chamber. In the second and third experimental runs (Figs. 11B, 11C), an additional sample of $\mathrm{CH}_{4}$-saturated water at $\sim 200$ psi pressure was released out the top of the inlet port. These samples of headspace gas and dis- 

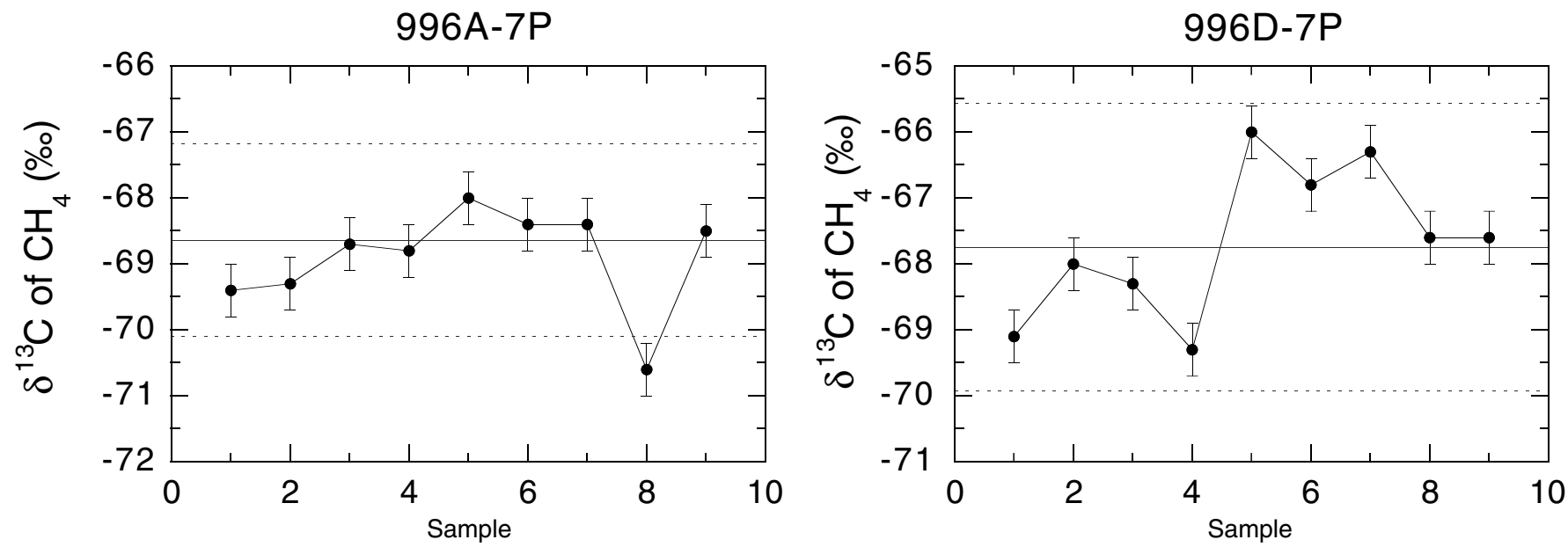

Figure 4. Times series plots of methane $\delta^{13} \mathrm{C}$ values from PCS cores at Site 996. Details as in Figure 2.

solved $\mathrm{CH}_{4}$ at $\sim 200$ psi were extracted before the water and gas had a chance to fully reequilibrate after the rapid pressure drop from $\sim 1000$ psi. The data for this lower pressure, unequilibrated system show a consistent $\delta^{13} \mathrm{C}$ fractionation of $1.5 \%$ - $2 \%$ o between the headspace gas and dissolved $\mathrm{CH}_{4}$, with headspace gas having lighter $\delta^{13} \mathrm{C}$ (Figs. 11B, 11C).

We conclude that the main factors contributing to carbon isotope fractionation during the degassing experiments are the release of gas from high pressure and the lack of equilibrium between water and gas that can occur after rapid pressure drops within the pressure vessel.

\section{DISCUSSION AND CONCLUSIONS}

Absolute values and downhole trends of $\mathrm{CH}_{4} \delta^{13} \mathrm{C}$ collected from gas voids in APC and XCB cores have been used by Paull et al. (Chap. 7, this volume) to make inferences on the origin and migration of $\mathrm{CH}_{4}$ on the Blake Ridge. Such interpretations are based on the fundamental assumption that limited fractionation of carbon isotopes occurs during core recovery despite an enormous loss of gas (Dickens et al., 1997).

Volumetrically weighted averages of $\mathrm{CH}_{4} \delta^{13} \mathrm{C}$ for gas samples collected at pressure by the PCS are the same as the $\mathrm{CH}_{4} \delta^{13} \mathrm{C}$ for gas samples collected from gas voids in normal APC and XCB cores. The relationship holds for PCS cores that contained relatively low and high total gas volumes. Thus, $\mathrm{CH}_{4} \delta^{13} \mathrm{C}$ data from gas voids appears to be representative of bulk in situ gas irrespective of the amount of gas lost. Interestingly, our conclusion for isotope fractionation of $\mathrm{CH}_{4}$ may not extend to the molecular distribution of hydrocarbon gases. Gas samples collected from the PCS are often significantly enriched in heavier hydrocarbons $\left(\mathrm{C}_{4}\right.$ through $\left.\mathrm{C}_{7}\right)$ when compared to gas samples collected from gas voids in APC and XCB cores (Paull, Matsumoto, Wallace, et al., 1996).

The isotopic values of the gas void and PCS gas samples indicate that $\mathrm{CH}_{4}$ in Blake Ridge sediments is largely microbial in origin (Paull et al., Chap. 7, this volume). Furthermore, the relatively constant $\delta^{13} \mathrm{C}$ values at depths greater than $\sim 300$ mbsf indicate that little or no addition of thermogenic gas occurs with increasing depth (Fig. $1)$. The cause of the systematic decreases in methane $\delta^{13} \mathrm{C}$ values observed at shallower depths is complex and is likely the result of upward migration of $\mathrm{CH}_{4}$ and $\mathrm{CO}_{2}$ coupled with Rayleigh fractionation during bacterially mediated $\mathrm{CO}_{2}$ reduction (Paull et al., Chap. 7, this volume).

At Sites 994, 995, and 997, the base of gas hydrate stability is present at a depth of $\sim 450 \mathrm{mbsf}$, and a bottom simulating reflector (BSR) occurs at approximately this level at Sites 995 and 997. Sev- eral lines of geochemical and geophysical evidence indicate that the BSR in this region of the Blake Ridge is the interface between $\mathrm{CH}_{4}$ hydrate-bearing sediments above and free gas-bearing sediments below (Paull, Matsumoto, Wallace, et al., 1996; Holbrook et al., 1996; Dickens et al., 1997). At Sites 995 and 997, no discontinuity is observed in methane $\delta^{13} \mathrm{C}$ values across the BSR (Fig. 1). This observation suggests that there is no significant equilibrium carbon isotopic fractionation in reactions involving $\mathrm{CH}_{4}$ hydrate, $\mathrm{CH}_{4}$-rich free gas, and dissolved $\mathrm{CH}_{4}$ in pore waters. Such an interpretation is consistent with studies of both natural and experimentally synthesized $\mathrm{CH}_{4}$ hydrate (Claypool et al., 1985; Pflaum et al., 1986; Sassen and MacDonald, 1997).

The $\mathrm{CH}_{4} \delta^{13} \mathrm{C}$ for individual gas samples collected during degassing of a single PCS core vary by as much as $9 \%$. The large range typically reflects an anomalous gas sample that was collected from a small volume of gas released from the PCS at high pressure. This observation suggests that kinetic fractionation of carbon isotopes can occur during rapid degassing of the PCS.

Simple analog degassing experiments demonstrate that kinetic effects associated with degassing can result in significant carbon isotope fractionation of $\mathrm{CH}_{4}$. The magnitude of this fractionation appears to increase with the complexity of the system that is being degassed. Thus, the experiments involving only pressurized $\mathrm{CH}_{4}$ show smaller isotope fractionations than do the experiments involving $\mathrm{CH}_{4}$-saturated water (up to $2 \%$ ). The carbon isotope fractionations that can occur during PCS degassing may reflect the complex system inside of the PCS, which can include $\mathrm{CH}_{4}$ gas, $\mathrm{CH}_{4}$ hydrate, $\mathrm{CH}_{4}-$ saturated water, and sediment located in multiple chambers separated by valves.

Dickens et al. (Chap. 11, this volume) have highlighted two additional factors that complicate any interpretation of data from PCS degassing experiments. First, significant quantities of $\mathrm{CH}_{4}$-poor borehole water fill the PCS during deployment and come into contact with the core after it is sealed in the pressurized housing. This leads to dilution of $\mathrm{CH}_{4}$ concentration in interstitial water in the sediment core and, in many cases, decomposition of $\mathrm{CH}_{4}$ hydrate before a degassing experiment begins. Second, degassing experiments were conducted after the PCS had equilibrated in an ice-water bath $\left(0^{\circ} \mathrm{C}\right)$. This temperature is significantly lower than in situ values in the formation before core recovery and could lead to additional $\mathrm{CH}_{4}$ hydrate formation before degassing began.

There are two main carbon isotope fractionation processes during PCS degassing experiments (Figs. 2-7). The first and most significant is during the initial degassing of high pressure $\mathrm{CH}_{4}$-poor air that is trapped inside the PCS during deployment. The second, which is on the order of $1 \%$ o- $2 \%$, occurs during release of larger volumes of 

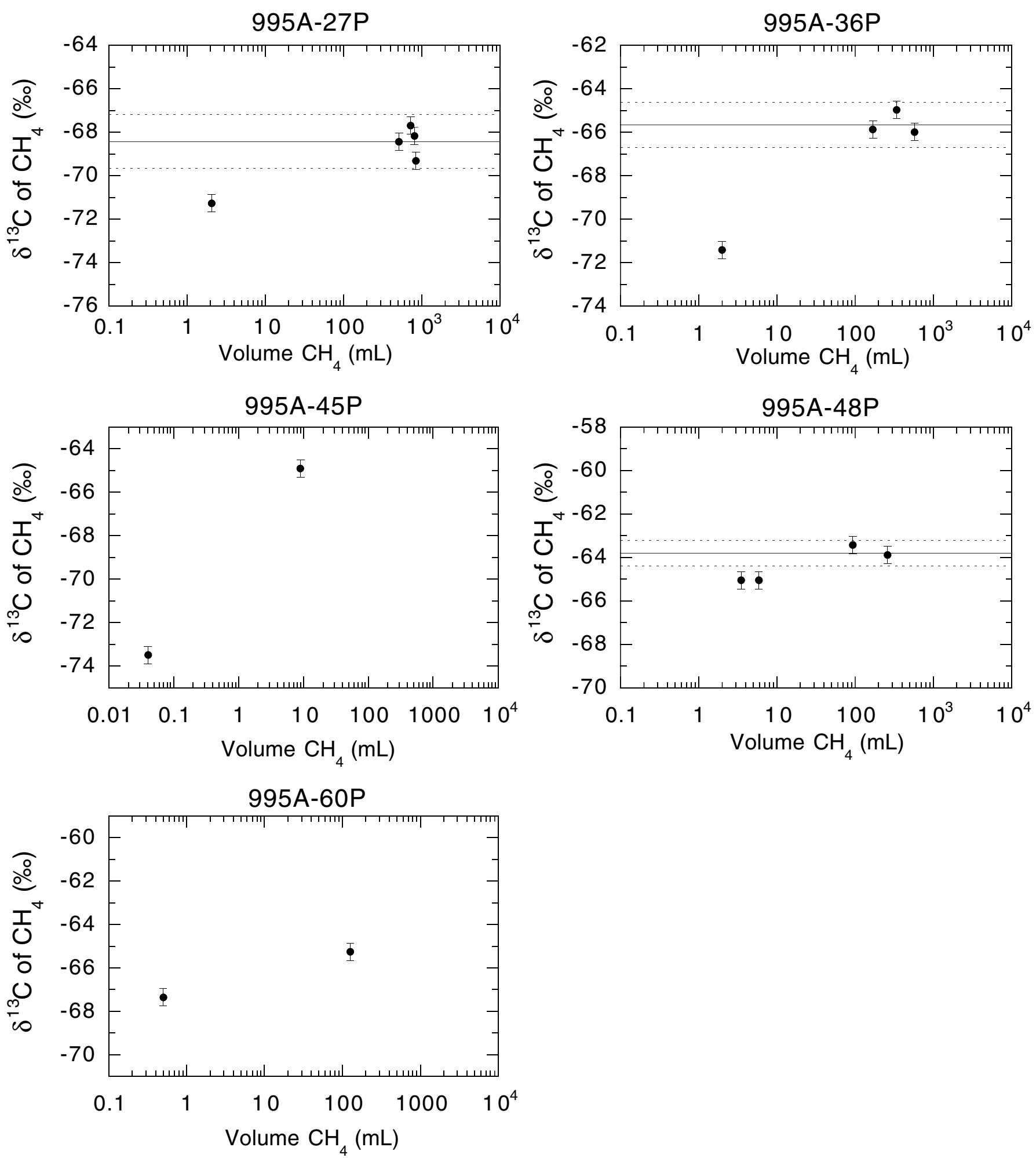

Figure 5. Methane $\delta^{13} \mathrm{C}$ values plotted against volume of $\mathrm{CH}_{4}$ (in $\mathrm{mL}$ ) released during stepwise degassing of PCS cores at Site 995 . Data for gas volumes are in Table 1 . The scale of the vertical axes is the same in all panels. Error bars show analytical uncertainties of 2 standard deviations ( $\pm 0.4 \%$ ). For each core, the average $\delta^{13} \mathrm{C}$ value calculated by weighting the individual measurements by the volume of $\mathrm{CH}_{4}$ released is shown by a horizontal line ( $\pm 2 \sigma$ uncertainty shown as dashed line). 

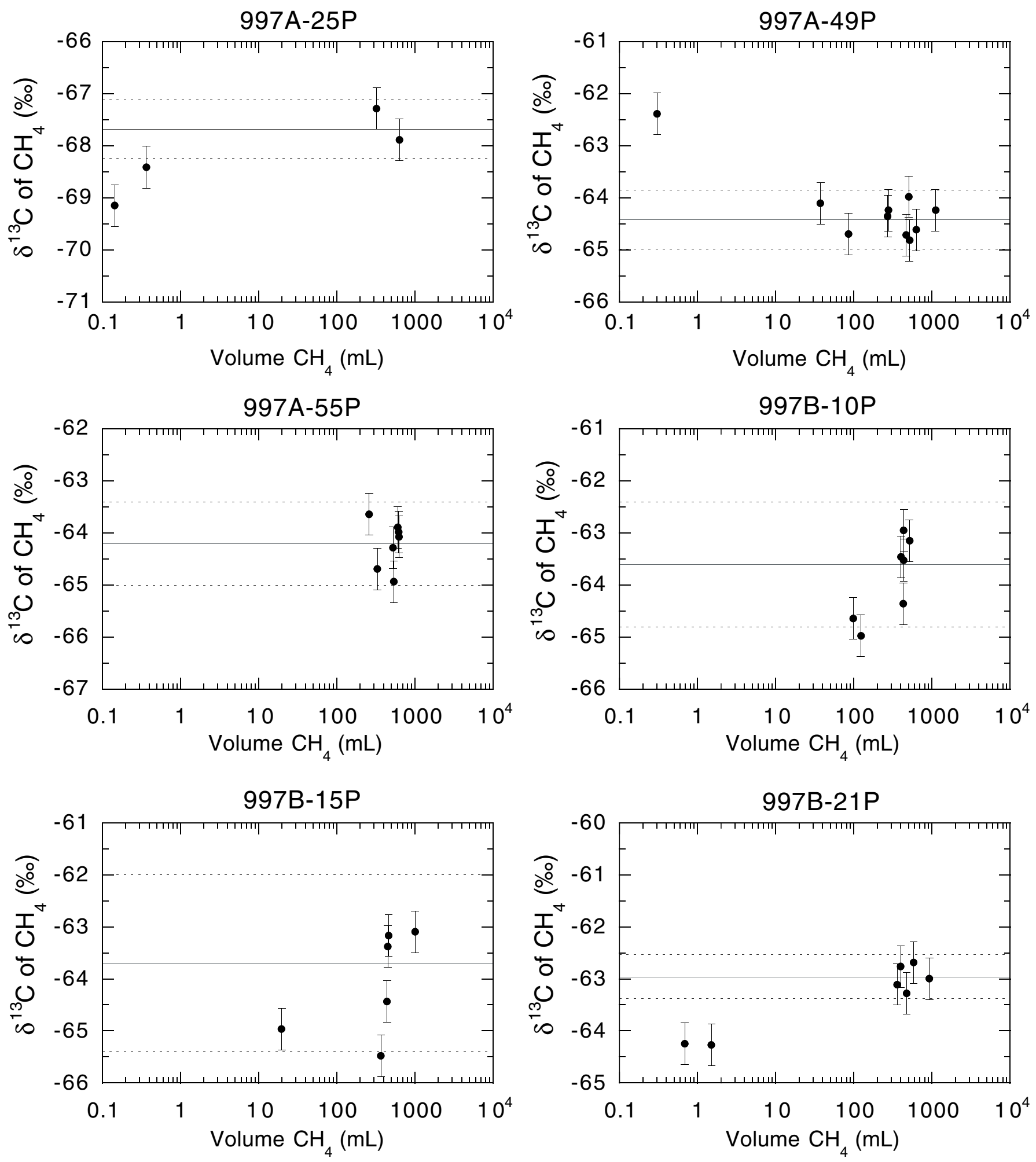

Figure 6. Methane $\delta^{13} \mathrm{C}$ values plotted against volume of $\mathrm{CH}_{4}$ (in $\mathrm{mL}$ ) released during stepwise degassing of PCS cores at Site 997 . Details as in Figure 5. 

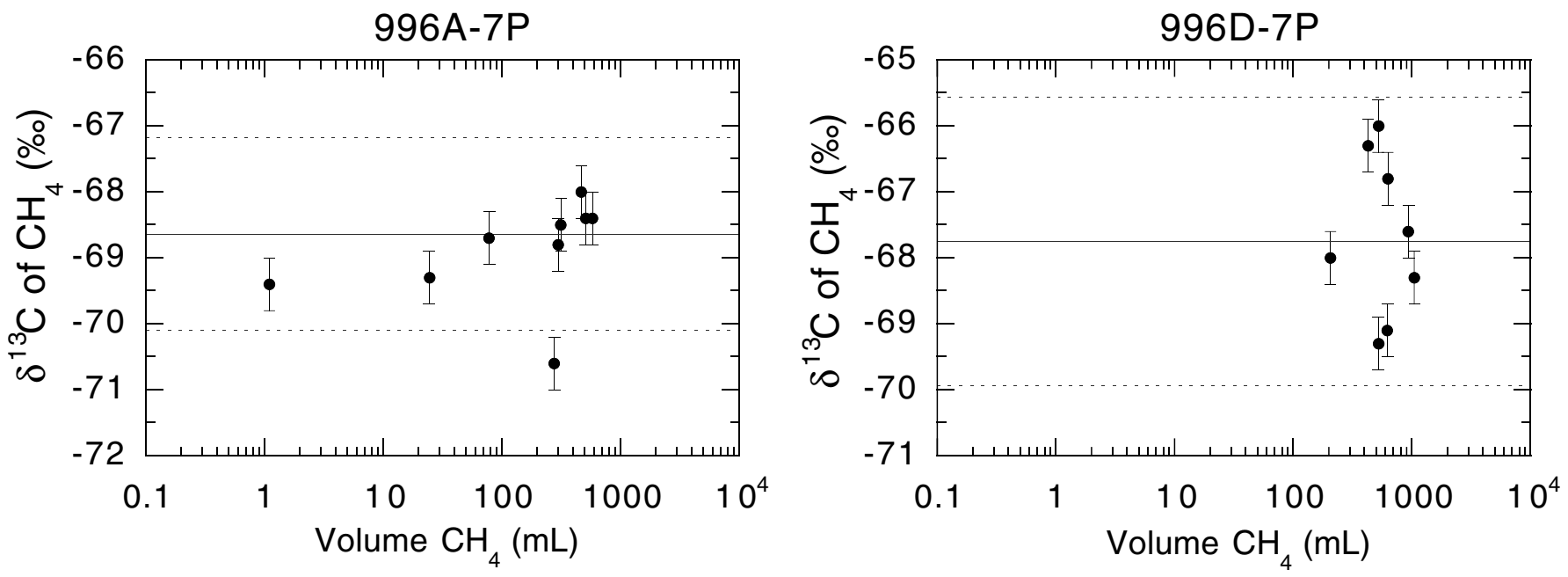

Figure 7. Methane $\delta^{13} \mathrm{C}$ values plotted against volume of $\mathrm{CH}_{4}$ (in $\mathrm{mL}$ ) released during stepwise degassing of PCS cores at Site 996 . Details as in Figure 5.

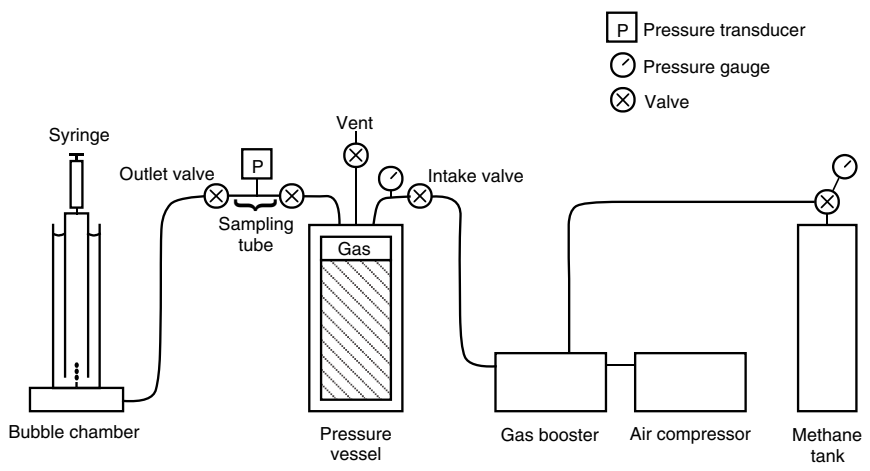

Figure 8. Experimental configuration for degassing of pressurized methane. Details are described in the text. Plastic spacers were used inside the pressure vessel to reduce the total gas volume. This made the void space inside the vessel comparable to that in the second set of experiments in which water was present in the vessel (see Fig. 9).

$\mathrm{CH}_{4}$. Based on comparison with the results of the analog degassing experiments, fractionations of this magnitude can be caused by (1) high-pressure release of headspace gas that is then bubbled through water, and (2) failure to allow the gas + water $\pm \mathrm{CH}_{4}$-hydrate system inside the PCS to reequilibrate after the large pressure drop associated with removal of an aliquot of gas. The effects of these processes are probably amplified when interstitial gas must escape through fine-grained sediment.

Solving the first problem, that of trapped air inside the PCS, would require modifying the deployment procedure and interior design of the PCS so that only water is initially present inside the pressure chamber. However, as demonstrated here, the effects of trapped air are relatively easy to recognize and do not pose a major problem in interpreting PCS gas data. During future experiments with the $\mathrm{PCS}$, the second problem (disequilibrium) can be minimized if gas is released in relatively small aliquots, resulting in small pressure drops, and if the PCS is allowed to reequilibrate at the new pressure before releasing another aliquot of gas. However, during Leg 164, the total time available for conducting a given PCS degassing experiment was limited by the need to prepare the tool for another coring run. A redesigned pressure core sampler that allows samples to be removed from

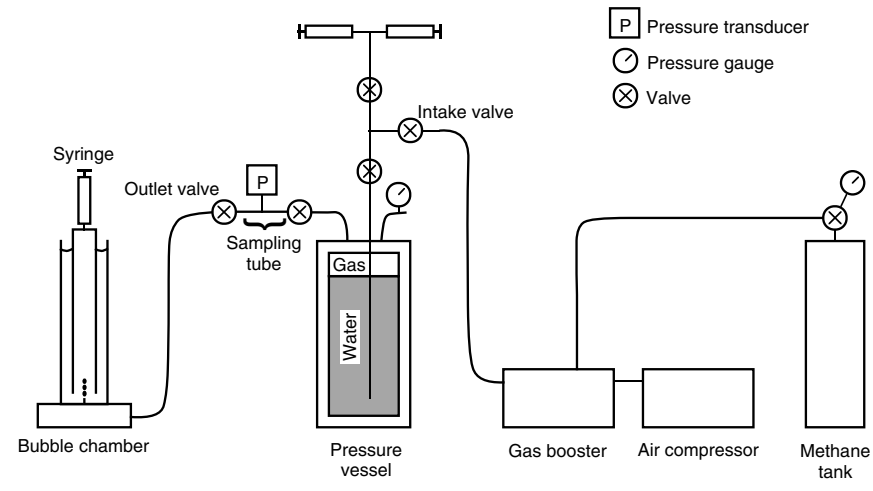

Figure 9. Experimental configuration for degassing of $\mathrm{CH}_{4}$-saturated water. Details are described in the text and the caption for Figure 11.

Table 2. Experimental data for degassing of pressurized methane.

\begin{tabular}{|c|c|c|c|}
\hline Run \# & $\begin{array}{l}\text { Pressure } \\
\quad(p s i)\end{array}$ & $\begin{array}{c}\text { Gas } \\
\text { volume } \\
(\mathrm{mL})\end{array}$ & $\begin{array}{c}\delta^{13} \mathrm{C}\left(\mathrm{CH}_{4}\right) \\
(\% \circ \mathrm{PDB})\end{array}$ \\
\hline $500-1$ & 553 & 390 & -43.5 \\
\hline $500-2$ & 537 & 420 & -43.7 \\
\hline $500-3$ & 522 & 350 & -43.6 \\
\hline $1000-1$ & 1019 & 420 & -43.8 \\
\hline $1000-2$ & 991 & 1200 & -44.3 \\
\hline $1000-3$ & 949 & 710 & -44.1 \\
\hline $1500-1$ & 1548 & 1400 & -43.6 \\
\hline $1500-2$ & 1502 & 1000 & -43.6 \\
\hline $1500-3$ & 1459 & 1100 & -44.6 \\
\hline $2000-1$ & 2014 & 950 & -43.5 \\
\hline $2000-2$ & 1949 & 1070 & -43.6 \\
\hline $2000-3$ & 1893 & 960 & -43.9 \\
\hline
\end{tabular}

Note: For the experiments conducted at 1500 and 2000 psi, all of the gas in the sampling tube could not be released at once, because the volume would have exceeded the capacity of the bubbling chamber. For these runs, the stated gas volume refers to the volume actually released to the bubbling chamber.

the tool while maintaining pressure would make it possible to degass samples as slowly as is necessary to ensure reequilibration between gas release steps. 
Table 3. Experimental data for degassing of $\mathrm{CH}_{4}$-saturated water.

\begin{tabular}{|c|c|c|c|c|c|}
\hline Run\#-sample\# & $\begin{array}{l}\text { Pressure } \\
\quad(\mathrm{psi})\end{array}$ & $\begin{array}{c}\text { Gas } \\
\text { volume } \\
(\mathrm{mL})\end{array}$ & $\begin{array}{c}\text { Water } \\
\text { volume } \\
(\mathrm{mL})\end{array}$ & $\begin{array}{c}\delta^{13} \mathrm{C}\left(\mathrm{CH}_{4}\right) \\
(\% \circ \mathrm{PDB})\end{array}$ & Comments \\
\hline $1-1$ & 1040 & - & - & -44.2 & Gas out top \\
\hline $1-2$ & 1040 & - & - & -43.8 & Gas out top \\
\hline $1-3$ & 1040 & 10.1 & 22.9 & -43.9 & Water + gas \\
\hline $1-4$ & 1040 & 12.1 & 16.6 & -44.2 & Water + gas \\
\hline $1-5$ & - & 32 & - & -44.2 & Standard \\
\hline $1-6$ & 1040 & 8.2 & 21.8 & -43.9 & Water + gas \\
\hline $1-7$ & 1040 & - & - & -43.1 & Headspace gas \\
\hline $1-8$ & 1040 & - & - & -44.4 & Headspace gas \\
\hline $1-9$ & 216 & - & - & -43.8 & Headspace gas \\
\hline $1-10$ & 216 & - & - & -44.6 & Headspace gas \\
\hline $2-1$ & 1040 & 41 & - & -44.1 & Gas out top \\
\hline $2-2$ & 1040 & 46 & - & -44.0 & Gas out top \\
\hline $2-3$ & 1040 & 10 & 11 & -43.6 & Water + gas \\
\hline $2-4$ & 1040 & 6.5 & 24 & -44.2 & Water + gas \\
\hline $2-5$ & - & 29 & - & -44.5 & Standard \\
\hline $2-6$ & 1040 & 5.5 & 20 & -43.9 & Water + gas \\
\hline $2-7$ & 1040 & 4.5 & 15 & -43.6 & Water + gas \\
\hline $2-8$ & 1040 & 59 & - & -43.7 & Headspace gas \\
\hline $2-10$ & 210 & 49 & - & -44.3 & Headspace gas \\
\hline $2-11$ & 210 & 3 & 1.5 & -42.7 & Water + gas \\
\hline $3-1$ & 898 & - & - & -43.0 & Gas out top \\
\hline $3-2$ & 898 & - & - & -44.4 & Gas out top \\
\hline $3-3$ & 898 & - & - & -43.8 & Gas out top \\
\hline $3-4$ & 898 & 8.9 & 7.2 & -43.7 & Water + gas \\
\hline $3-5$ & - & - & - & -43.9 & Standard \\
\hline $3-6$ & 898 & 20 & 5.9 & -44.0 & Water + gas \\
\hline $3-7$ & 898 & 18 & 4.1 & -44.0 & Water + gas \\
\hline $3-8$ & 898 & 23 & 4.8 & -44.0 & Water + gas \\
\hline $3-9$ & 898 & - & - & -43.1 & Headspace gas \\
\hline $3-10$ & 898 & - & - & -43.7 & Headspace gas \\
\hline $3-11$ & 199 & - & - & -44.5 & Headspace gas \\
\hline $3-12$ & 199 & 19 & 3 & -42.8 & Water + gas \\
\hline $3-13$ & 199 & 19 & 3 & -43.3 & Water + gas \\
\hline
\end{tabular}

Notes: For descriptions of terms in the Comments column, see caption for Figure 11. $—=$ samples for which volumes were not measured.

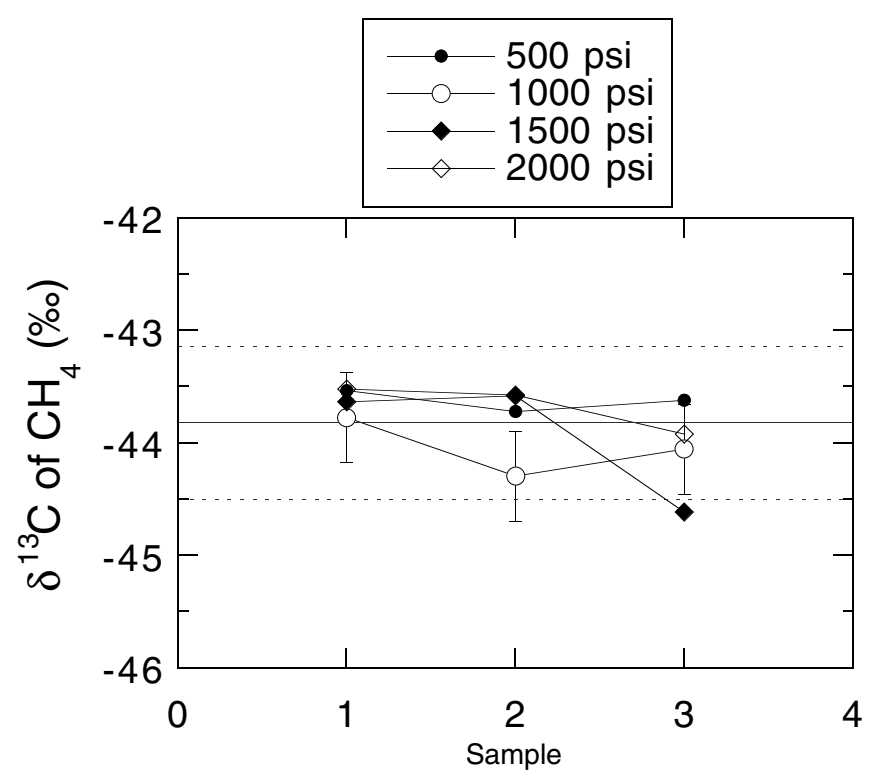

Figure 10. Times series plots of methane $\delta^{13} \mathrm{C}$ values from pressurized methane degassing experiments. Data are in Table 2.

\section{ACKNOWLEDGMENTS}

We would like thank T. Pettigrew and M. Stahl for constructing the PCS, M. Stahl, J. Hohnberg, and M. Kawasaki for operating the
PCS during core collection, and W. Borowski and H. Wehner for assistance with the PCS degassing experiments. Funding for this work was provided by the Joint Oceanographic Institutions U.S. Science Support Program. High-pressure equipment was acquired through an NSF grant to G. Brass and M. Kastner to build an Isothermal Gas Hydrate Decomposition System (IDAS). We would also like to thank R. Sassen and A. Waseda for numerous suggestions that improved the final manuscript.

\section{REFERENCES}

Claypool, G.E., and Kaplan, I.R., 1974. The origin and distribution of methane in marine sediments. In Kaplan, I.R. (Ed.), Natural Gases in Marine Sediments: New York (Plenum), 99-139.

Claypool, G.E., Threkheld, C.N., Mankiewicz, P.N., Arthur, M.A., and Anderson, F.T., 1985. Isotopic composition of interstitial fluids and origin of methane in slope sediment of the Middle America trench, Deep Sea Drilling Project Leg 84. In von Huene, R., Aubouin, J., et al., Init. Repts. DSDP, 84: Washington (U.S. Govt. Printing Office), 683-691.

Dickens, G.R., Paull, C.K., Wallace, P., and the ODP Leg 164 Scientific Party, 1997. Direct measurement of in situ methane quantities in a large gas-hydrate reservoir. Nature, 385:427-428.

Holbrook, W.S., Hoskins, H., Wood, W.T., Stephen, R.A., Lizzarralde, D., and the Leg 164 Science Party, 1996. Methane gas-hydrate and free gas on the Blake Ridge from vertical seismic profiling. Science, 273:18401843

Kvenvolden, K.A., Barnard, L.A., and Cameron, D.H., 1983. Pressure core barrel: application to the study of gas hydrates, Deep Sea Drilling Project Site 533, Leg 76. In Sheridan, R.E., Gradstein, F.M., et al., Init. Repts. DSDP, 76: Washington (U.S. Govt. Printing Office), 367-375.

Paull, C.K., Matsumoto, R., Wallace, P.J., et al., 1996. Proc. ODP, Init. Repts., 164: College Station, TX (Ocean Drilling Program). 
Pettigrew, T.L., 1992. The design and operation of a wireline pressure core sampler (PCS). ODP Tech. Note, 17.

Pflaum, R.C., Brooks, J.M., Cox, H.B., Kennicutt, M.C., and Sheu, D.-D., 1986. Molecular and isotopic analysis of core gases and gas hydrates, Deep Sea Drilling Project Leg 96. In Bouma, A.H., Coleman, J.M., Meyer, A.W., et al., Init. Repts. DSDP, 96: Washington (U.S. Govt. Printing Office), 781-784.

Sassen, R., and MacDonald, I.R., 1997. Hydrocarbons of experimental and natural gas hydrates, Gulf of Mexico continental slope. Org. Geochem., 26:289-293.
Date of initial receipt: 23 April 1998

Date of acceptance: 12 January 1999 Ms 164SR-209

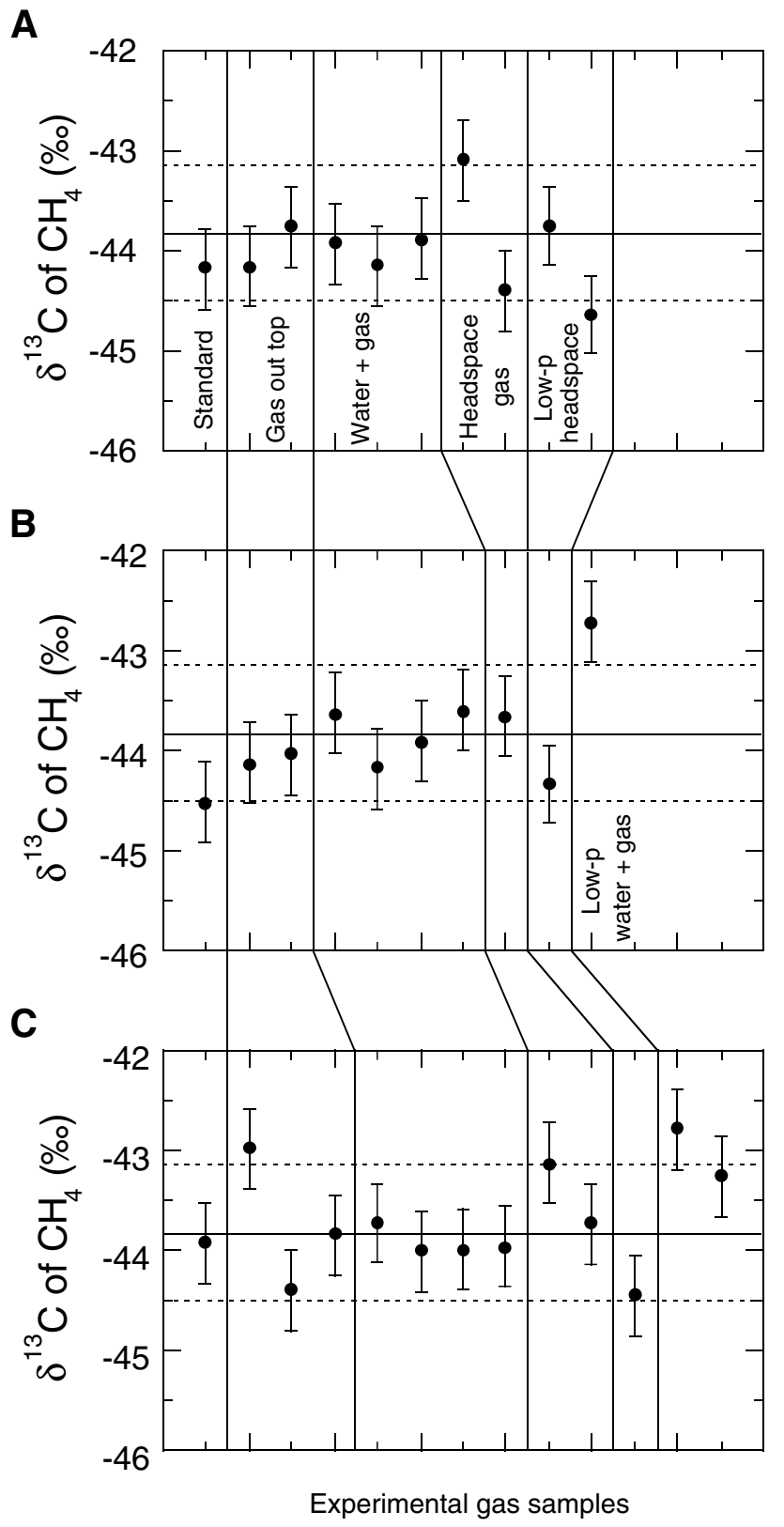

Figure 11. Methane $\delta^{13} \mathrm{C}$ values of gas samples from experiments on degassing of $\mathrm{CH}_{4}$-saturated water. Data are in Table 3. "Standard" refers to a sample of gas that was isolated at pressure in the $\mathrm{T}$ above the inlet port to the pressure vessel while the vessel was equilibrating (see Fig. 9). This gas was released into a syringe before the samples of headspace gas and $\mathrm{CH}_{4}$-saturated water were taken. Similarly, "gas out top" refers to high-pressure methane that was extracted from the pressure vessel through the vertical portion of the inlet tube after the "standard" sample was taken. "Water + gas" refers to $\mathrm{CH}_{4}$-saturated water extracted out of the top of the inlet port. This water effervesced vigorously as it entered the syringes, and all gas released from solution was trapped in the syringe. "Headspace gas" is a sample of gas that was isolated in the sampling tube (see Fig. 9) before release of $\mathrm{CH}_{4}$-saturated water. This gas was released into the bubbling chamber where it could be sampled using syringes. Release of $\mathrm{CH}_{4}$-saturated water caused a large pressure drop inside the pressure vessel. Several minutes after this pressure drop occurred, a new sample of headspace gas (which undoubtedly contained some $\mathrm{CH}_{4}$ just released from solution) was isolated in the sampling tube and then released to the bubbling chamber. In the second and third experimental runs ( $\mathbf{B}$ and $\mathbf{C}$ ), an additional sample of $\mathrm{CH}_{4}$-saturated water at lower pressure was released out the top of the inlet port. The average ( $\pm 2 \sigma$ uncertainty) $\mathrm{CH}_{4} \delta^{13} \mathrm{C}$ of methane used in the experiments, based on data from the pressurized methane release experiments (Table 2; Fig. 10), is shown by the solid and dashed lines. 